\title{
CAREERS
}

POSTDOCS NIH committee calls for workforce reforms $\mathbf{p . 5 6 1}$
PROFESSIONAL DEGREES Most graduates from new programmes head to industry $\mathbf{p . 5 6 1}$
NATUREJOBS For the latest career listings and advice www.naturejobs.com

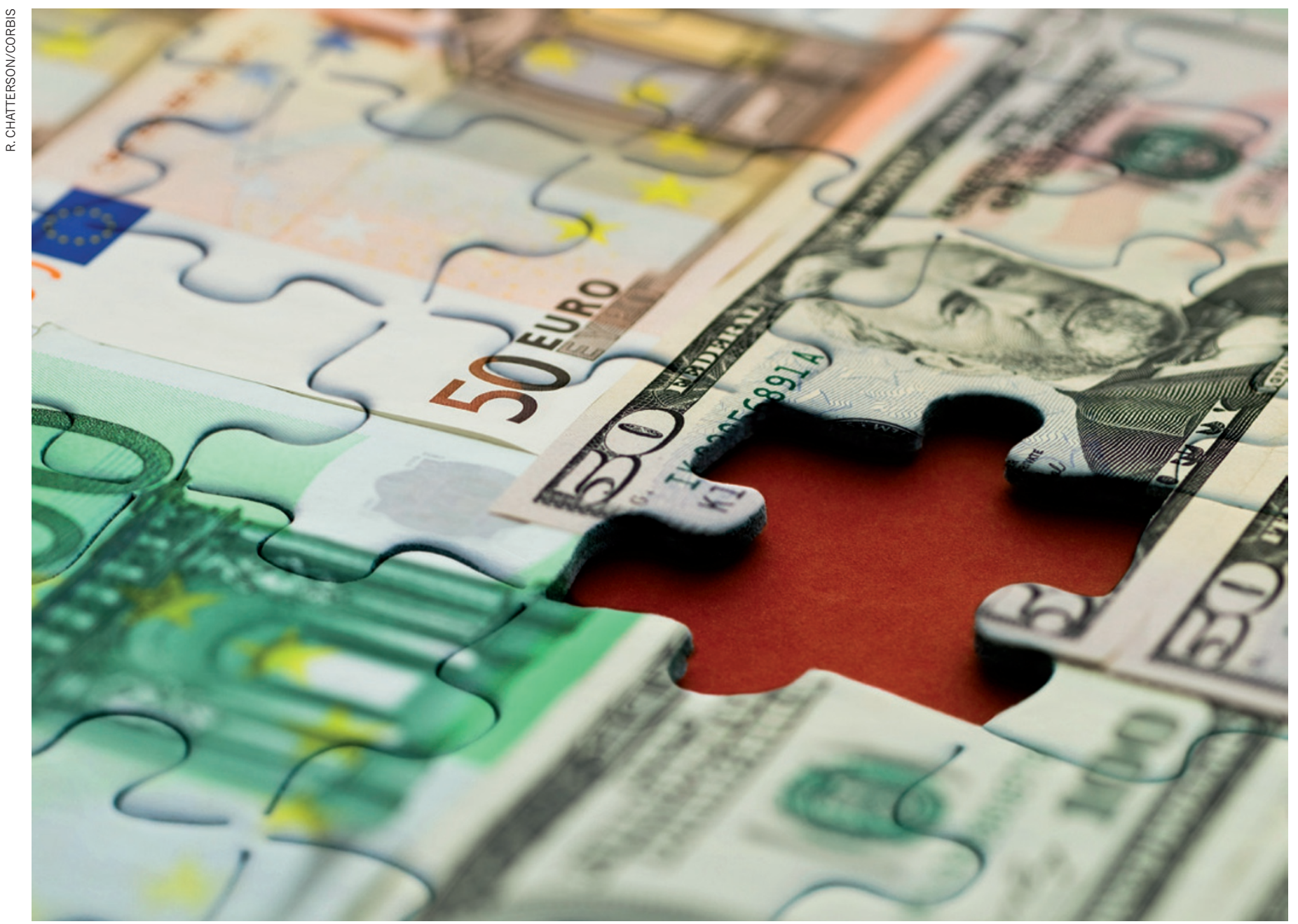

\section{GRANT APPLICATIONS}

\section{Find me the money}

Some consultants offer to help researchers to find and secure grants. But scientists should carefully consider whether and how a consultant is worth the time and expense.

\section{BY LUCAS LAURSEN}

$\mathrm{T}$ The e-mails were arriving in Pete Kissinger's inbox almost every day: "TODAY ONLY: Extra 25\% Off... Craft your R01 Grants Management... Only 1 Day Left." They were from consultants trying to charge him to do something that scientists have long done for themselves: search for research-grant opportunities, write proposals and, in some cases, manage the grant once it has been won. Eventually, Kissinger's curiosity got the better of him.

Having founded his first company in the 1970s, Kissinger, an entrepreneur and bioanalytical chemist who works part-time at Purdue University in West Lafayette, Indiana, is no stranger to the challenges of raising start-up capital and research money. But he says that it is harder to get funding now than when he began. For one thing, the paperwork is more onerous. "And that's not really the thing most of us in science enjoy doing," he says. So about 18 months ago, when he needed money to develop a device for sampling blood to speed up clinical diagnoses, Kissinger hired FreeMind, a funding consultancy with offices 
in Boston, Massachusetts, and in Jerusalem. He is waiting for decisions on two applications that he made last year with their help, and on another that was put together in March.

Types of funding finder range from services offering online information packs that cost a few hundred dollars to consulting firms such as FreeMind, which can charge up to $10 \%$ of the grant total. In return, they offer familiarity with the applications process and established relationships with the programme officers and businesses that are offering the funds. Nothing stops a scientist from going directly to the US National Science Foundation for funding information, notes Ram May-Ron, vice-president of FreeMind. "We don't claim to have any special powers, but we have lots of experience."

Consultants say that they can help to highlight and emphasize the aspects of a proposal that increase the chances of funding. "It's not just about how you raise money, it's about how to direct what you're doing in a fashion that will extract the social, medical and financial value of it," says Mark Goldstein, chief scientific officer of MammaCare, a medical-device firm based in Gainesville, Florida. Goldstein has worked with Kirk Macolini, a funding finder at Centurion Technologies in Ithaca, New York, for more than 10 years.

Making the most of that help means knowing when to seek assistance, whom to ask for it and how to work well with a consultant.

\section{REACHING OUT}

The emergence of funding finders reflects the growing specialization and competition in science. Just as postdocs and technicians handle the nitty-gritty of experiments so that principal investigators can concentrate on guiding their laboratory's research, some lab leaders are also seeking help with finding, winning and maintaining funding. "The nice thing is he does it all, from soup to nuts. It's free and clear of my office," says Ajit Varki, a glycobiologist at the University of California, San Diego, who hired Macolini to help him to get funding for a pharmaceutical start-up now called Sialix, based in Vista, California.

But hiring a funding finder itself requires careful planning. Researchers must consider how they will work with the consultant and other project collaborators to make the most of the time invested in the grant application. It helps to understand that funding finders cannot do all the work themselves. "If somebody drops an idea in our lap and says, "Write a proposal', it would be quite difficult," says Ian Eden, a senior consultant at Arttic in Derby, UK. "We work with them, not on our own." Researchers need to set aside time to discuss their goals, answer technical questions about their research, evaluate suggestions from the consultant and produce and execute a strategy based on those discussions.

However, young researchers should begin by seeking funding advice from their home

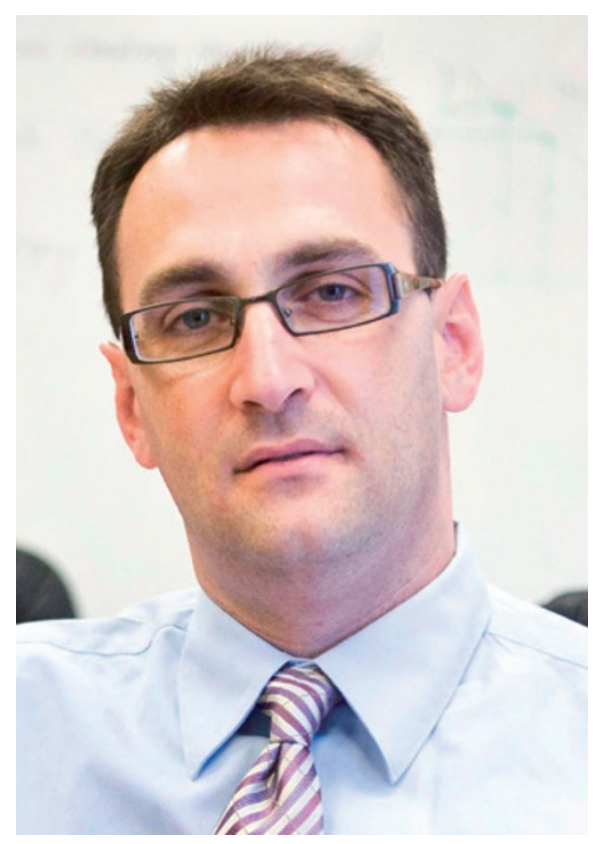

Ram May-Ron's consultancy shows researchers how to maximize their chances of winning a grant.

institutions, says Alan Rebar, executive director of Discovery Park, a research-coordination centre at Purdue that organizes networking events with other grant seekers. Universities often skim off a percentage of their researchers' grants for overhead costs and devote administrative resources to helping scientists seek funding, so they usually prefer researchers to seek help internally, and may even prohibit them from using university funds to pay outsiders. The situation can become complicated, however, when researchers want to transfer their research from the academic to the commercial sector. "I can't use university resources to do an outside business application," says Kissinger.

Funding finders all say that their clients have higher success rates on average than scientists acting alone, although such claims are impossible to verify. The US National Institutes of Health reports that $11 \%$ of applications to the first round of its Small Business Innovation Research grants, which aim to help small businesses to commercialize research results, are successful. May-Ron says that $30-40 \%$ of his clients' applications for those grants are successful.

In addition to proposal-writing help, some firms offer networking tips and strategic guidance. Gonzalo de Silva, a consultant at the Euro-Funding Advisory Group in Madrid, notes that to be eligible for many European grants, research teams must include scientists in different countries as well as an industry partner; funding finders can help to make connections between potential collaborators. "That's where we add the most value, because we have a lot of contacts with businesses and experience," says de Silva.

Funding consultants tend to deal repeatedly with the same contacts in business and 
at funding bodies, so they can build up an understanding of what such people are looking for. "If you have absolutely no clue as to what the interest of the programme officers is, then you really have no chance," says May-Ron. "We try to close this gap through conversations with programme officers and researchers." By talking to programme officers about a project idea before submitting the proposal, he explains, a consultant might learn that the funder puts increased value on certain components of the application. "So we tell the scientist to focus on those," says May-Ron.

In other cases, programme officers might mention that they are about to open a call for proposals, giving the consultant time to alert a client. The applicant could get such information for free by contacting a programme officer directly, but making dozens of requests to keep on top of all opportunities would be very time-consuming. And consultants can get to know a programme officer's preferences and interests. May-Ron recalls a case where one programme officer encouraged one of his clients, an influenza researcher, to submit a proposal in response to a call with guidelines that did not actually specify influenza research as a candidate area. The researcher won the award.

\section{THE RIGHT CHOICE}

Once scientists are convinced that they or their projects would benefit from external consultancy, they have to choose a firm. Universities sometimes contact grant consultants to supplement their in-house staff, notes Rebar, so researchers might be able to get a list of contacts. Or they could do some digging for themselves: Goldstein found Macolini through an Internet search.

The size of a potential project will make a difference to the type of consultancy the researcher should approach. Arttic, like many large firms, won't work on grants

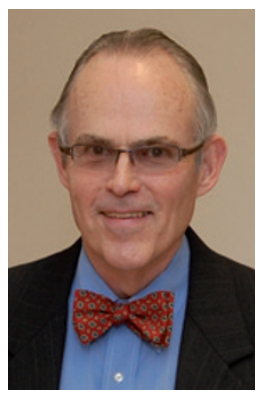

"It's really easy to submit a long proposal. It's much harder to write a short one."

Pete Kissinger smaller than about $€ 10$ million (US\$13 million), says Eden, and its fee is $5-7 \%$ of the grant money.

Macolini's fees include an upfront project charge and a percentage-based success fee, with the proportions varying from project to project. This creates a higher initial cost for the researcher than does a contingency fee alone, but consultants argue that it helps to prevent researchers sending them half-baked ideas just because they have nothing to lose when the grants don't materialize.

Researchers can ask for references from consultants' previous clients, but should treat them with caution. "The scientist has to evaluate the record of the consultants," says de Silva. There are no obvious ways of comparing one company's claimed success rate with another's, because they have no reporting requirements and different scientific disciplines have different funding constraints, which could affect success. However, it is possible to compare companies' years of experience and the number of grants they have facilitated, as well as the types of grants and collaborations.

Goldstein says he chose Macolini because he had a history of helping "really bright" research teams, an apparently sincere interest in the project and a willingness to offer criticism. It is particularly important to make sure that the scientist's and the consultant's aims are compatible, because one project may lead to another. "You need someone to tell you when you're barking up the wrong tree," says Goldstein.

\section{MAKING THE MOST OF IT}

The more information researchers share, the more likely the consultants are to be able to find funding for the project - or improve the odds of winning a grant. "We try to fully understand their project and regroup and rearrange them to reflect what funding sources would expect to see," says MayRon. That could mean recommending that a researcher restrict an application to one avenue of research and hold off on another. Or it could mean bringing in components from other disciplines to strengthen a proposal.

The consultant runs through multiple drafts and revisions of the proposal in cooperation with the investigator, boiling down the content until it is simple, succinct and a good match for the ideas of the programme officers. "It's really easy to submit a long proposal. It's much harder to write a short one," says Kissinger. External reminders make it easier to hit goals, he adds: "They help find opportunities, keep you on track with the format and make you remember deadlines." In addition to the technical help, says Goldstein, good funding finders offer strategic advice. During brainstorming sessions, Macolini asks business-type questions such as how long it will take to explore an idea and what the client will do next with it. The ability to do that comes from "having a leg in each field”, says Goldstein.

It is still too early for Kissinger to know whether his funding-finding gamble will pay off. But at least his inbox is now overflowing not with marketing e-mails, but with tailored messages from his own consultant.

Lucas Laursen is a freelance journalist based in Madrid, Spain.

\section{POSTDOCS}

\section{Pay rise recommended}

Biomedical postdoctoral researchers supported by US National Institutes of Health (NIH) fellowships should earn US\$42,000 in their first year, with 4-6\% increases in each of years two to seven, says an NIH committee report. Released on 14 June and commissioned by NIH director Francis Collins, the report offers recommendations to ease long training periods and overproduction of PhDs. It advises that NIH-supported postdocs receive the same benefits as employed colleagues, including health insurance, retirement plans and paid time off; calls to double the number of Early Independence awards, which speed postgraduates into careers and skip excessive postdoctoral training; and recommends training grants to prepare graduate students for varied career paths.

\section{PROFESSIONAL DEGREES}

\section{Career paths mixed}

Most graduates of professional science master's (PSM) degree programmes in the United States go on to work in industry, according to an independent analysis that used social media to track employment outcomes. Of more than 1,800 graduates tracked, some two-thirds now have industry positions. About one-quarter of the graduates are pursuing a university position or another degree, and fewer than $8 \%$ are working at nonprofit organizations or in government. PSM degrees were initially designed to meet industry needs, although many programmes are now expanding, says Michael Teitelbaum, senior adviser to the Alfred P. Sloan Foundation in New York, which supported development of the PSM and funded the analysis. "These are very encouraging data," he says.

\section{PHD PROGRAMMES}

\section{Universities must evolve}

$\mathrm{PhD}$ students at US universities need better preparation for careers outside academia, says a report released on 14 June by the US National Academies in Washington DC in response to a congressional directive. Research Universities and the Future of America makes ten recommendations, including a call to use research collaborations to align graduate programmes more closely with business. It also recommends that the US government attract and retain talent by streamlining immigration processes. 